\title{
Microstructural, Mechanical, and Durability Related Similarities in Concretes Based on OPC and Alkali-Activated Slag Binders
}

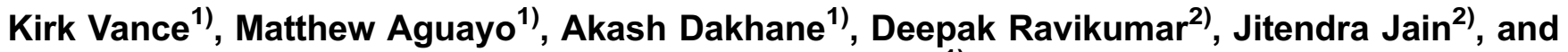 \\ Narayanan Neithalath ${ }^{1), *}$
}

(Received February 20, 2014, Accepted May 26, 2014)

\begin{abstract}
Alkali-activated slag concretes are being extensively researched because of its potential sustainability-related benefits. For such concretes to be implemented in large scale concrete applications such as infrastructural and building elements, it is essential to understand its early and long-term performance characteristics vis-à-vis conventional ordinary portland cement (OPC) based concretes. This paper presents a comprehensive study of the property and performance features including early-age isothermal calorimetric response, compressive strength development with time, microstructural features such as the pore volume and representative pore size, and accelerated chloride transport resistance of OPC and alkali-activated binder systems. Slag mixtures activated using sodium silicate solution $\left(\mathrm{SiO}_{2}\right.$-to- $\mathrm{Na}_{2} \mathrm{O}$ ratio or $\mathrm{M}_{\mathrm{s}}$ of 1-2) to provide a total alkalinity of $0.05\left(\mathrm{Na}_{2} \mathrm{O}-\right.$ tobinder ratio) are compared with OPC mixtures with and without partial cement replacement with Class F fly ash (20\% by mass) or silica fume ( $6 \%$ by mass). Major similarities are noted between these binder systems for: (1) calorimetric response with respect to the presence of features even though the locations and peaks vary based on $\mathrm{M}_{\mathrm{s}}$, (2) compressive strength and its development, (3) total porosity and pore size, and (4) rapid chloride permeability and non-steady state migration coefficients. Moreover, electrical impedance based circuit models are used to bring out the microstructural features (resistance of the connected pores, and capacitances of the solid phase and pore-solid interface) that are similar in conventional OPC and alkali-activated slag concretes. This study thus demonstrates that performance-equivalent alkali-activated slag systems that are more sustainable from energy and environmental standpoints can be proportioned.
\end{abstract}

Keywords: alkali-activated slag, isothermal calorimetry, microstructure, durability, chloride transport, electrical impedance.

\section{Introduction}

The demand for constructed facilities has been increasing in both the developed and the developing world, and ordinary portland cement (OPC) concrete is among the most used materials in infrastructure. The greenhouse gas emissions associated with Portland cement production (Mehta 2007) ${ }^{1}$ necessitate the development of alternate cementitious materials to replace a part of OPC concretes, and alkaliactivated aluminosilicates are among the novel materials that are expected to fit this bill. Aluminosilicate materials such as fly ash and blast furnace slag, which are by-product materials from other industries, when used for concrete production, makes concrete more sustainable from a resource and energy viewpoint.

\footnotetext{
${ }^{1)}$ School of Sustainable Engineering and the Built

Environment, Arizona State University, Tempe, AZ 85287, USA.

*Corresponding Author; E-mail: Narayanan.Neithalath@ asu.edu

${ }^{2)}$ Solidia Technologies, Piscataway, NJ, USA.

Copyright ( $\odot$ The Author(s) 2014. This article is published with open access at Springerlink.com
}

Alkaline activation of waste or by-product aluminosilicates such as fly ash or slag has been reported (Duxson et al. 2007; Palomo et al. 1999; Provis and Van Deventer 2009; Pacheco-Torgal et al. 2008; Shi et al. 2006), with adequate mechanical and durability properties (Fernández-Jiménez et al. 1999; Bernal et al. 2012; Pacheco-Torgal et al. 2012; Ravikumar et al. 2010). The use of low calcium fly ashes as precursors generally require heat curing to obtain desirable properties, even though slow strength gain at ambient temperatures has also been reported. Hence ground granulated blast furnace slag or a combination of fly ash and slag (Chithiraputhiran and Neithalath 2013) is employed for ambient temperature cured alkali-activated systems. In addition, a fairly rigorous understanding of slag as a cementitious material exists, and alkali activation of slag also produces $\mathrm{C}-\mathrm{S}-\mathrm{H}$ gel as the reaction product, similar to OPC systems but typically with a lower $\mathrm{Ca} / \mathrm{Si}$ ratio (Yip et al. 2005; Song et al. 2000). This has led to extensive studies on the alkali activation of slag (Fernández-Jiménez et al. 1999; Bernal et al. 2012; Ravikumar et al. 2010; Chithiraputhiran and Neithalath 2013; Ravikumar and

\footnotetext{
${ }^{1}$ Estimated OPC production of 3.2 billion tons in 2012 results in about $5 \%$ of the global $\mathrm{CO}_{2}$ emissions being attributed to cement production.
} 
Neithalath 2012a). The depolymerized silica in slag results in higher dissolution rates under alkaline conditions. Caustic alkalis or alkali compounds whose anions can react with $\mathrm{Ca}^{2+}$ to form compounds less soluble than calcium hydroxide can act as activators for slag. The use of sodium silicate based activators $\left(\mathrm{Na}_{2} \mathrm{SiO}_{3} \cdot x \mathrm{H}_{2} \mathrm{O}+\mathrm{NaOH}\right)$ has been found to be ideal to produce desired mechanical properties (Fernández-Jiménez et al. 1999; Chithiraputhiran and Neithalath 2013; Chang 2003; Altan and Erdoğan 2012) even though alkali hydroxides, carbonates, and sulfates also have been reported to be used as activating agents (Shi et al. 2006). The nature and type of the activating agent determines the reaction rate and extent, and the reaction products formed, thereby exerting a significant influence on the earlyand later-age properties of alkali-activated binder systems (Chithiraputhiran and Neithalath 2013; Ravikumar and Neithalath 2012a, b; Puertas et al. 2004; Hajimohammadi et al. 2011). The energy requirement towards the production of activators and the associated environmental impact also plays an important role in determining the sustainability of alkali-activated systems, along with their potential to replace large amounts of OPC.

In order for novel cementitious systems such as alkaliactivated slags to gain acceptance in the concrete industry, it is imperative to have a thorough understanding of the properties and performance of these concretes vis-à-vis conventional OPC concretes. While several studies have reported comparisons between any one property of conventional and alkali-activated concretes, there have been no comprehensive studies that look at the early-age and laterage mechanical, microstructural, and durability (including alkali leaching and efflorescence) characteristics of these different materials. This study intends to bridge that knowledge gap by performing detailed studies on early-age reaction kinetics, strength development with time as a function of activator characteristics or cement replacement materials, microstructure and reaction products, and chloride transport resistance of conventional and activated concretes. Only waterglass-activated slag concretes are evaluated so as to keep the discussions succinct. The comparisons are made between the activated concretes and OPC concretes with and without partial cement replacement materials. Since most of the modern concretes contain high performance cement replacement materials such as fly ash or silica fume, such concretes are also proportioned in an attempt to position the alkali-activated concretes based on its relative performance.

\section{Experimental Program}

\subsection{Materials}

As part of this study, OPC concretes, both plain and modified by cement replacement materials, and alkali-activated slag concretes were proportioned. For the OPC pastes and concretes, Type I OPC conforming to ASTM C 150 was used. A class F fly ash conforming to ASTM C 618, or a dry densified silica fume conforming to ASTM C 1240 were used as partial cement replacement materials. The alkali- activated slag paste and concrete mixtures were prepared using ground granulated blast furnace slag conforming to ASTMC 989. The chemical compositions of all these materials are provided in Table 1.

Waterglass (sodium silicate) solution was used as the activating agent for slag. The as-obtained waterglass solution had a silica modulus (ratio of $\mathrm{SiO}_{2}-\mathrm{to}-\mathrm{Na}_{2} \mathrm{O}$ in the activator, termed $\mathrm{M}_{\mathrm{s}}$ ) of 3.26. Since it was previously observed that lower $\mathrm{M}_{\mathrm{s}}$ values are needed for desired levels of activation, $\mathrm{NaOH}$ solution was added to bring the $\mathrm{M}_{\mathrm{s}}$ to desired levels $\left(1.0,1.5\right.$, and 2.0 in this study). The ratio of $\mathrm{Na}_{2} \mathrm{O}$-to-the total powder (n) was maintained as 0.05 .

\subsection{Paste, Mortar, and Concrete Mixtures}

$\mathrm{OPC}$ and alkali-activated slag paste mixtures were used for isothermal calorimetry studies to evaluate the heat release response of these pastes. OPC mixtures were proportioned by replacing $0-20 \%$ of OPC by fly ash and $0-12 \%$ of OPC by silica fume, by mass. However the results for $20 \%$ cement replacement and $6 \%$ silica fume replacement alone are reported in this study to keep the comparisons focused. The water-to-cementing materials ratio $(\mathrm{w} / \mathrm{cm})$ used for the paste mixtures was 0.40 . For the alkali-activated paste mixtures, the liquid-to-powder ratio $(1 / \mathrm{p})$ used was 0.50 because the use of an $1 / p$ of 0.40 resulted in a mixture of lower workability. The liquid consists of water that is added, along with the liquid portion of the waterglass solution, which was $60 \%$. It should be noted that no workability enhancing aids were used. The $1 / p$ used for the alkali-activated mortar and concrete mixtures were 0.40 . The binder content used for the concrete mixtures was $400 \mathrm{~kg} / \mathrm{m}^{3}$ while the mortar mixtures had a $50 \%$ aggregate volume. Limestone aggregates and river sand was used. The concrete specimens were cast in cylinders $(100 \mathrm{~mm}$ diameter and $200 \mathrm{~mm}$ height) and moist cured at $23 \pm 2{ }^{\circ} \mathrm{C}$ and $98 \% \mathrm{RH}$ until the testing time.

\subsection{Test Methods}

\subsubsection{Calorimetry and Porosimetry on Pastes}

Isothermal calorimetry experiments were carried out in accordance with ASTM C 1679. The pastes were mixed externally and loaded into the isothermal calorimeter. The time elapsed between the instant water or the activating solution was added to the powder and the paste loaded into the calorimeter was around 2-3 min. The tests were run for 48 or $72 \mathrm{~h}$ with the calorimeter set at $25^{\circ} \mathrm{C}$. Mercury intrusion porosimetry (MIP) was performed on small samples of pastes (both conventional and activated) oven-dried at $60{ }^{\circ} \mathrm{C}$ for $2 \mathrm{~h}$. This treatment procedure was found to yield similar total pore volumes and critical pore sizes as a more involved vacuum drying method and hence was used in this study. A mercury intrusion porosimeter that can generate a maximum pressure of $414 \mathrm{MPa}$ and evaluate a minimum pore diameter of $0.003 \mu \mathrm{m}$ was used. The test, after 28 days of hydration, was performed in two steps - the low pressure step evacuates the gases, fills the sample holder with mercury, and carries out the test up to $345 \mathrm{kPa}$, and the high pressure step reaches pressures of up to $414 \mathrm{MPa}$. The 
Table 1 Chemical compositions of the binder materials.

\begin{tabular}{|c|c|c|c|c|}
\hline Composition ( $\%$ by mass) & Slag & $\mathrm{OPC}$ & Silica fume & Fly ash \\
\hline Silica $\left(\mathrm{SiO}_{2}\right)$ & 36.0 & 20.2 & 93.4 & 50.24 \\
\hline Alumina $\left(\mathrm{Al}_{2} \mathrm{O}_{3}\right)$ & 10.5 & 4.7 & 0.42 & 28.78 \\
\hline Iron oxide $\left(\mathrm{Fe}_{2} \mathrm{O}_{3}\right)$ & 0.67 & 3.0 & 0.52 & 5.72 \\
\hline Calcium oxide $(\mathrm{CaO})$ & 39.8 & 61.9 & 1.91 & 5.86 \\
\hline Magnesium oxide $(\mathrm{MgO})$ & 7.93 & 2.6 & - & 1.74 \\
\hline Sodium oxide $\left(\mathrm{Na}_{2} \mathrm{O}\right)$ & 0.27 & 0.19 & 0.25 & 0.20 \\
\hline Potassium oxide $\left(\mathrm{K}_{2} \mathrm{O}\right)$ & 0.80 & 0.82 & 0.79 & 0.84 \\
\hline Sulfur trioxide $\left(\mathrm{SO}_{3}\right)$ & 2.1 & 3.9 & 0.34 & 0.51 \\
\hline Loss on ignition & 3.0 & 1.9 & 2.3 & 2.8 \\
\hline $\begin{array}{l}\text { Specific surface area }\left(\mathrm{m}^{2} /\right. \\
\mathrm{kg})\end{array}$ & $487^{\mathrm{a}}$ & $453^{\mathrm{a}}$ & $13,000^{\mathrm{b}}$ & $322^{\mathrm{a}}$ \\
\hline
\end{tabular}

a Determined using Blaine's air permeability apparatus.

${ }^{\mathrm{b}}$ Obtained from the manufacturer of silica fume.

contact angle and surface tension values used were $130^{\circ}$ and $0.485 \mathrm{~N} / \mathrm{m}$ respectively for both the OPC and alkali-activated pastes. Accurate determination of these values could result in changes in the extracted pore structure features but the variations are expected to be minor in nature that does not influence the behavioral interpretations.

\subsubsection{Mechanical and Durability Tests on Concretes}

The compressive strengths of the concrete mixtures were determined in accordance with ASTM C 39. Rapid chloride permeability (RCP, ASTM C 1202) and Non-steady state migration (NSSM, NT BUILD 492 1999) tests were carried out on $50 \mathrm{~mm}$ thick discs cut from $200 \mathrm{~mm}$ long cylindrical specimens cured for 28, 56, or 90 days. For the RCP test, the specimens were conditioned by vacuum saturation, and enclosed in a cell flanked by reservoirs that contain $0.3 \mathrm{~N}$ $\mathrm{NaOH}$ solution on one side and $3 \% \mathrm{NaCl}$ solution on the other. A $60 \mathrm{~V}$ potential difference was applied between the electrodes placed on both faces of the specimen, for a duration of $6 \mathrm{~h}$. The total charge passed (in coulombs) at the end of $6 \mathrm{~h}$ of testing is reported as the RCP value. This test is well-accepted for conventional concretes (even though a number of drawbacks have been reported), and has been used recently for alkali-activated concrete systems also (Ravikumar and Neithalath 2013; Neithalath and Ravikumar 2013; Bernal et al. 2011). For the NSSM test, the specimens were preconditioned by vacuum saturation with calcium hydroxide solution. The catholyte and anolyte solutions used were $2 \mathrm{~N} \mathrm{NaCl}$ and $0.3 \mathrm{~N} \mathrm{NaOH}$ respectively. The test duration was maintained at $24 \mathrm{~h}$ and the voltage at $30 \mathrm{~V}$ for all the cases. After the test duration, the specimens were axially split and sprayed with a $0.1 \mathrm{M}$ silver nitrate solution. The depth of chloride penetration was measured based on the precipitation of white silver chloride. The non-steady state migration coefficient $\left(D_{n s s m}\right)$ in $\mathrm{m}^{2} / \mathrm{s}$ is given as (NT BUILD 492 1999):

$$
\begin{aligned}
& D_{n s s m}=\frac{R T}{z F E} \frac{x_{d}-\alpha \sqrt{x_{d}}}{t} \\
& \alpha=2 \sqrt{\frac{R T}{z F E}} \operatorname{erf}^{-1}\left(1-\frac{2 c_{d}}{c_{0}}\right)
\end{aligned}
$$

$E=(U-2) / L$, where $U$ is the absolute voltage $(\mathrm{V}), L$ is the specimen thickness in $\mathrm{m}, z$ is the valence of the chloride ion, $F$ is the Faraday constant, $R$ is the molar gas constant, $T$ is the average value of initial and final temperatures in $\mathrm{K}, x_{d}$ is the average value of the penetration depth in $\mathrm{m}, t$ is the test duration in seconds, $c_{d}$ is the chloride concentration at which silver nitrate changes to silver chloride $(0.07 \mathrm{~N})$, and $c_{0}$ is the chloride concentration of the catholyte solution $(2 \mathrm{~N})$. The value of $c_{d}$ chosen is the one generally used for ordinary portland cement concretes. However, the calculations for the migration coefficients were repeated with $c_{d}$ values of 0.05 and 0.10 , but this resulted in insignificant changes to the $D_{n s s m}$ value. Hence a $c_{d}$ value of 0.07 itself is used in this study.

\subsubsection{Electrical Impedance Spectroscopy}

Electrical impedance spectroscopy (EIS) was carried out on the concrete specimens prior to the chloride transport tests. The test configuration for EIS was the same as that used for the chloride transport tests (both RCP and NSSM tests). Similar arrangements have been reported in (Neithalath and Ravikumar 2013; Neithalath and Jain 2010; Schwarz and Neithalath 2010; Jain and Neithalath 2011). EIS spectra were obtained using an impedance gain-phase analyzer operating at a frequency range of $1 \mathrm{~Hz}-10 \mathrm{MHz}$. A $250 \mathrm{mV}$ AC signal was employed and 10 measurements per decade of frequency were recorded. The meeting point of the bulk and electrode arcs in a Nyquist plot (plot of real vs. imaginary impedance) is denoted as the bulk resistance $\left(R_{b}\right)$. The effective conductivity of the specimen $\left(\sigma_{e f f}\right)$ was calculated as: 


$$
\sigma_{e f f}=\frac{L}{R_{b} A}
$$

where $L$ is the length $(50 \mathrm{~mm})$, and $A$ is the cross sectional area $\left(7,854 \mathrm{~mm}^{2}\right)$ respectively of the specimen. The experimentally obtained Nyquist plots were simulated using equivalent circuit electrical models, which will be described later in this paper.

\section{Results and Discussions}

This section reports the results of early age hydration response, compressive strength, pore structure, and chloride transport resistance of conventional and alkali-activated slag concretes and facilitates a comparison of their properties.

\subsection{Early Age Reaction Response and Compressive Strength}

Isothermal calorimetric response and compressive strength of conventional and modified (with fly ash or silica fume) OPC pastes/mortars as well as waterglass activated slag pastes/mortars are discussed in this section. Figure $1 \mathrm{a}, \mathrm{b}$ show the heat release rate (heat released per $g$ of binder) and cumulative heat curves respectively of plain cement paste and those modified using $20 \%$ fly ash or $6 \%$ silica fume, for the first $48 \mathrm{~h}$ of hydration. The reactions were carried out at a temperature of $25^{\circ} \mathrm{C}$. Note that the response is normalized by the mass of binder (and not of the cement alone). The most notable observations from the heat release rate curve is that the use of either fly ash or silica fume as cement replacement results in reduced heat release peak magnitudes for the major hydration signature, with the fly ash modified paste showing the lowest heat release peak. The slopes of the acceleration region is also slightly higher for the OPC paste. Similar results have been reported in (Vance et al. 2013; Kumar et al. 2013). This is because: (1) replacement of $20 \%$ of cement by a rather slow-reacting material such as fly ash reduces the rate and extent of the reaction at early ages, and (2) the presence of fine particles of silica fume, even when considered to be acting as nucleation sites for the cement grains to hydrate (Neithalath et al. 2009) and thereby enhancing the hydration, results in a lower heat release peak due to the dilution effect being dominant. It is also likely that the agglomeration effect of some of the silica fume particles results in the lower heat release rate for that mixture because agglomerated particles do not act as effective nucleation sites. The changes in ultimate heat released after $48 \mathrm{~h}$ for all the three pastes investigated are also in line with these observations, as shown in Fig. 1b. When the heat release rate and cumulative heat released are normalized by the cement content in lieu of the binder content, the differences in the calorimetric responses are found to be very minimal (corresponding graphs not shown in this paper).

Figure $2 \mathrm{a}, \mathrm{b}$ depict the heat release rate and cumulative heat released for the waterglass activated slag pastes proportioned using $M_{s}$ values of $1.0,1.5$, and 2.0 respectively.
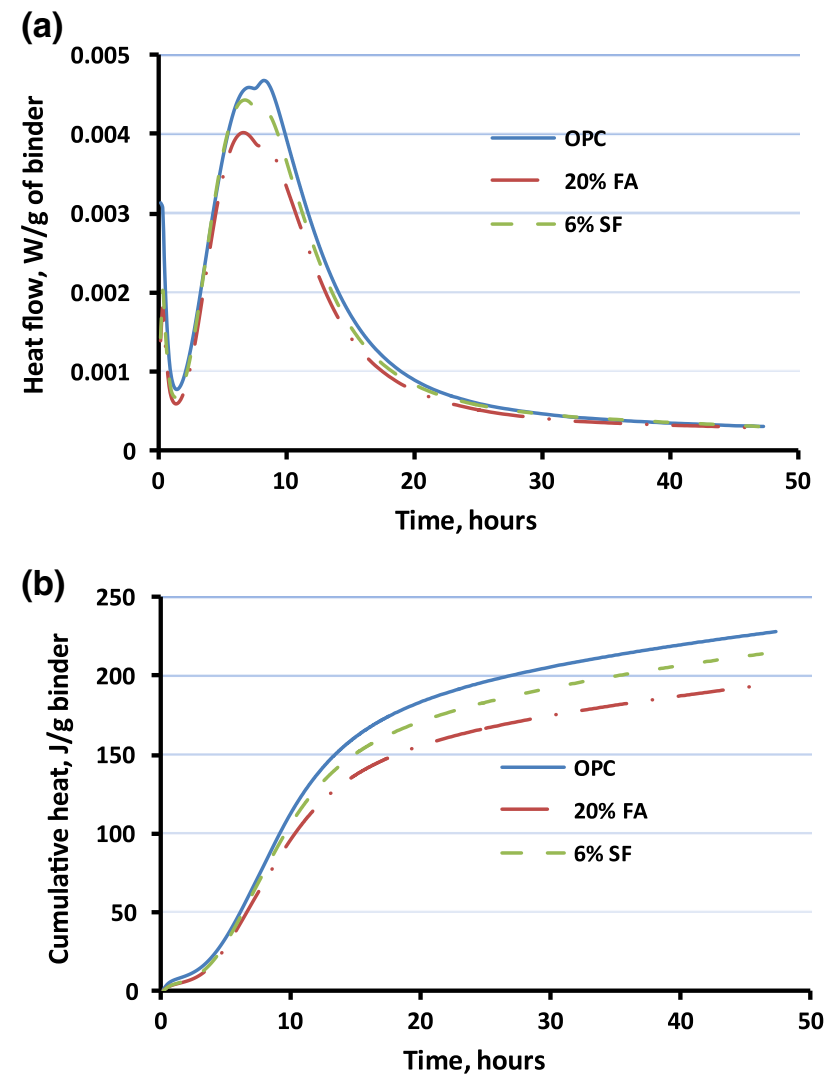

Fig. 1 a Heat release rate and $\mathbf{b}$ cumulative heat released for plain and modified cement pastes.

The heat release response rate has a shape resembling that of OPC pastes, but the locations and magnitudes of the features of the curve are different. The dormant periods for all the alkali-activated slag pastes are much longer than those of the OPC based systems: 7-18 h depending on the activator $M_{s}$ as opposed to $1-1.5 \mathrm{~h}$ for the OPC systems. A reduction in $M_{s}$ of the activator (by adding $\mathrm{NaOH}$ solution) results in the main reaction peak shifting to earlier times, and increasing in intensity. Even then, the main reaction peak is only about half as intense as the OPC hydration peak, which is demonstrated also through the lower total heat of reaction of the alkali-activated binders in Fig. 2b. The reduction in the main peak intensity in alkali-activated slags as compared to OPC systems can be attributed to a faster product layer formation around the slag particles immediately after the ionic concentrations in the pore solution reaches the critical value (i.e., immediately after the induction period) thereby inhibiting further reaction. It could also be postulated that the C-(A)-S-H gel formed in alkali-activated slags are more amorphous, with a consequent lower exothermicity in formation than the $\mathrm{C}-\mathrm{S}-\mathrm{H}$ gel from OPC hydration.

It is expected by further decreasing the $M_{s}$, the dormant periods can be reduced even more and the total reaction rate at early ages, as evidenced by the main peak heights, can be increased. However, there is little benefit to improving the early age reaction rates in activated slag pastes by decreasing the $M_{s}$ (or increasing the $\mathrm{Na}_{2} \mathrm{O}$ content in the mixture) because the later-age strengths are found to be higher at 
higher $M_{S}$ values (or higher silica contents) as will be shown in a forthcoming section.

When the total heat released at the end of $48 \mathrm{~h}$ for OPC and modified pastes and $72 \mathrm{~h}$ for the activated slag pastes (note that the steady state is not reached until about $60 \mathrm{~h}$ for the high $M_{s}$ value pastes) are compared, it can be noticed that a distinct plateau is observed for the activated slag pastes, corresponding to the very long dormant period. It has been shown that increasing the reaction temperature also results in reducing the extent of this plateau, as is the use of higher alkalinity (either through increase in the $\mathrm{Na}_{2} \mathrm{O}$-topowder ratio (n) or reducing the $M_{s}$ ) (Chithiraputhiran and Neithalath 2013; Ravikumar and Neithalath 2012a). Figure $2 \mathrm{~b}$ also shows that the cumulative heat of the mixture with a higher $M_{s}$ tends to approach that of the lower $M_{s}$ mixture after $72 \mathrm{~h}$, and the trends indicate a higher cumulative heat for the higher $M_{s}$ mixture at a much longer duration. This is substantiated by the compressive strength results shown below.

Figure $3 \mathrm{a}$ and $3 \mathrm{~b}$ show the compressive strength development as a function of time for the plain and modified OPC mortars and alkali-activated slag mortars. The silica fume modified mortar shows higher early age strengths and a 28-day strength that is comparable to the plain OPC mortar. The fly ash modified mortar demonstrates lower compressive strengths at early ages, and approaches that of the plain OPC mortar at 28 days, as is expected. For the alkali-activated slag mortars, an increase in $M_{s}$ value of the activator results in increased compressive strengths, especially after 14 days or so. While a higher alkalinity (as indicated by a lower $M_{S}$ )

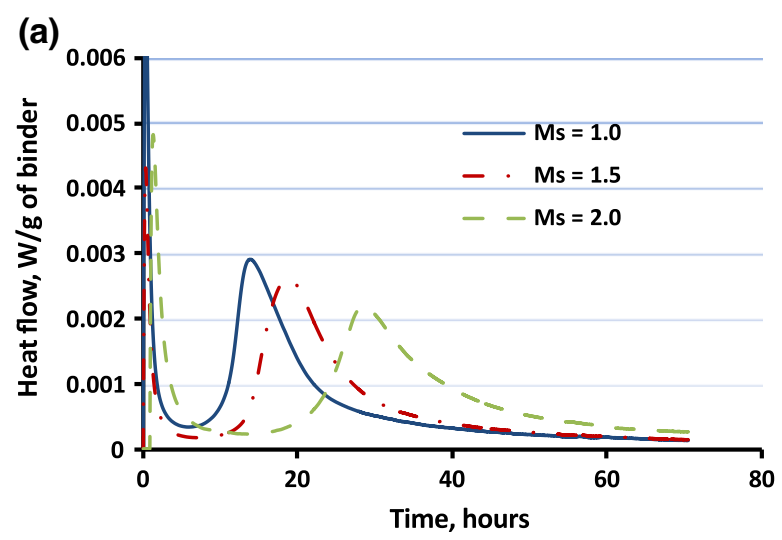

(b)

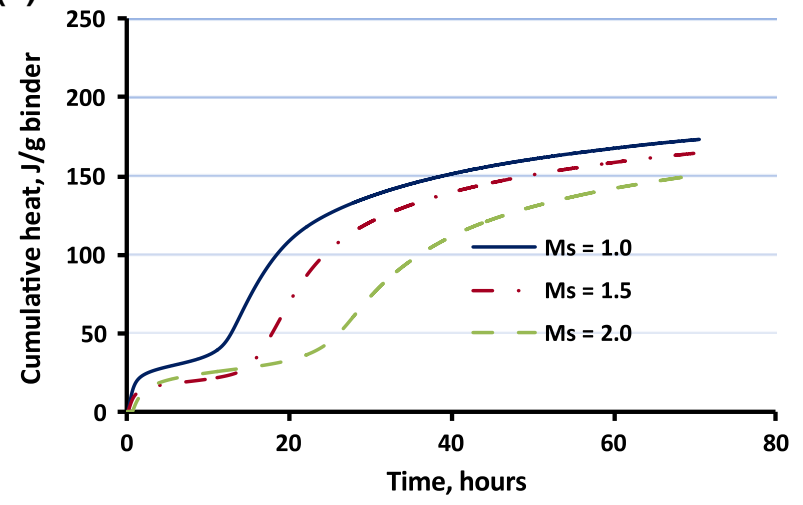

Fig. 2 a Heat release rate and $\mathbf{b}$ cumulative heat released for the alkali-activated slag pastes. is beneficial at early times to aid in dissolution of the glassy species in slag as shown by the heat release curves shown in Fig. 2a, a higher silica content is ultimately necessary to form the strength imparting $\mathrm{C}-(\mathrm{A})-\mathrm{S}-\mathrm{H}$ gel in the alkaliactivated systems (Hajimohammadi et al. 2011; Ravikumar and Neithalath 2012b). The alkali cations could also be incorporated into the $\mathrm{C}-(\mathrm{A})-\mathrm{S}-\mathrm{H}$ gel. Higher reactive silica content also helps form a $\mathrm{C}-(\mathrm{A})-\mathrm{S}-\mathrm{H}$ gel with an overall lower $\mathrm{Ca} / \mathrm{Si}$ ratio, which contributes to better properties (akin to the $\mathrm{C}-\mathrm{S}-\mathrm{H}$ gel formed from pozzolanic reaction). From a compressive strength standpoint, it can be noticed From Fig. 3 that the higher $M_{s}$ waterglass activated slag mortar has a very similar compressive strength as that of the plain OPC mortar after 28 days of moist curing. It also needs to be stated here that increasing the $M_{s}$ beyond 2.0 retards the reaction to a larger extent because of the lack of alkali hydroxides to facilitate initial dissolution, thereby not forming the reaction products, and thus inhibits property development. A value of 2.0 is considered to the optimal value of $M_{S}$ in the chosen range from the viewpoint of reaction kinetics and mechanical property development.

\subsection{Pore Structure and Product Constitution in Conventional and Alkali-Activated Pastes}

As shown in the previous section, the conventional OPC mortars and alkali-activated slag mortars show similar 28-day compressive strengths. It is therefore instructive to examine their pore structure, which is the focus of this
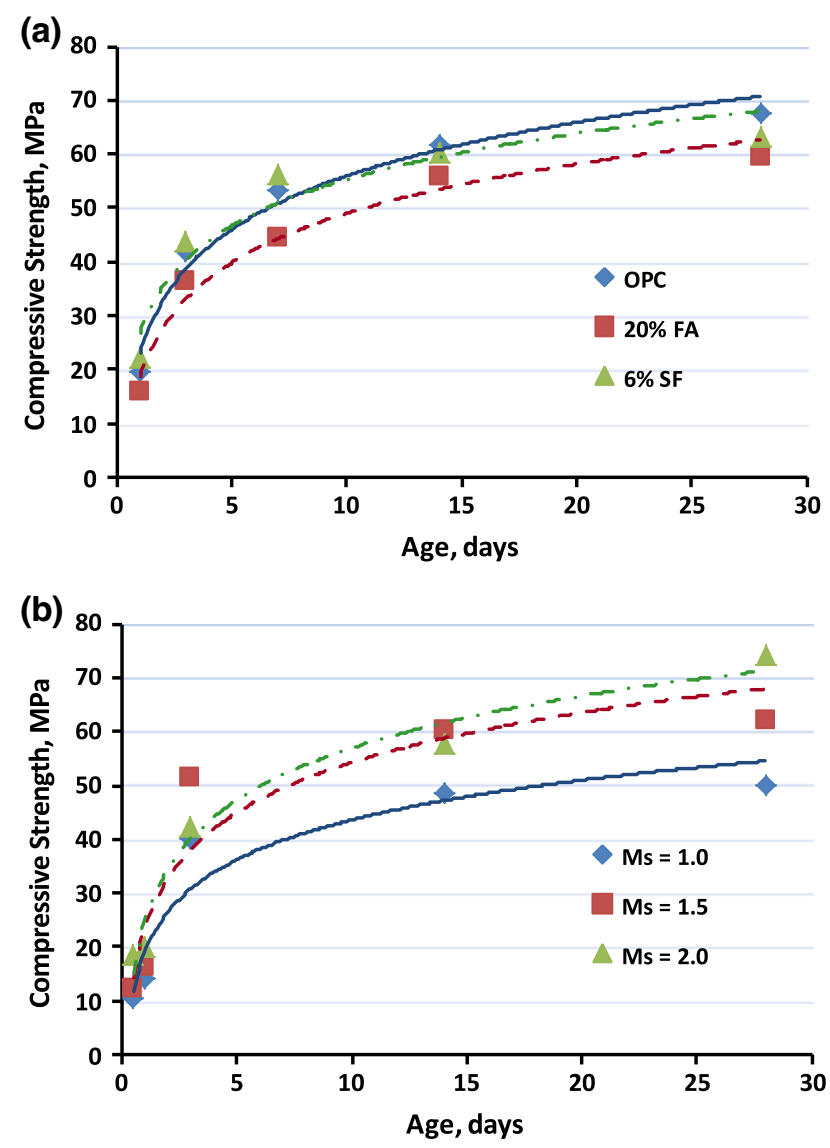

Fig. 3 Compressive strength development of: a OPC mortars and $\mathbf{b}$ alkali-activated slag mortars. 
section. The pore structure of these systems is also influential in their transport (moisture and ionic) performance which is a key determinant of their durability. Since the highest compressive strength was obtained for the activated mixture with an $M_{s}$ of 2.0 in this study, this paste is used for the pore structure and reaction product studies along with a plain OPC paste. 28-day old pastes are used for the analysis. Mercury intrusion porosimetry (MIP) is used to investigate the pore structure of these pastes. The use of MIP as an indicator of the total pore volume is well-accepted, but its use for pore size determination has several drawbacks (Diamond 2000; Moro and Böhni 2002), primarily because of the presence of "pore-throats" in cement pastes and similar systems. Mercury cannot intrude into some of the larger pores until the applied pressure is large enough to saturate the pore throats. However, an indication of the threshold pore diameter, ideally not as an absolute value, but as a parameter to facilitate comparison between specimens, can be obtained from the differential pore volume-pore diameter relationships (Atahan et al. 2009). While the resistance to high pressure could vary depending on the type of the matrix, its effects are not considered in this paper based on the fact that these matrices are shown to demonstrate similar compressive strengths.

Figure $4 \mathrm{a}$ shows the results from the MIP experiments for the OPC and alkali-activated slag pastes having an activator $M_{s}$ of 2.0 (w/c or $1 / \mathrm{p}$ of 0.40 , cured under sealed conditions for 28 days). The total pore volume intruded after a pressure of $414 \mathrm{MPa}$ was exerted is $0.10 \mathrm{~cm}^{3}$ of mercury per $\mathrm{g}$ of the sample for the OPC paste and $0.12 \mathrm{~cm}^{3} / \mathrm{g}$ for the alkaliactivated slag paste. Since the alkali-activated paste is slightly less dense than the OPC paste, the total porosity of these pastes can also be considered to be fairly similar (in the range of 20-23\%). From Fig. 4a, it can also be noticed that the pore size-pore volume curve drops rapidly for the alkaliactivated slag paste in the pore diameter range of $0.03-0.13 \mu \mathrm{m}$, whereas the distribution for the OPC paste is much more uniform in the pore diameter range of $0.01-1.0 \mu \mathrm{m}$.

The critical pore sizes or the threshold pore sizes are taken as the sizes corresponding to the maximum in the pore diameter (D) $-\mathrm{dV} / \mathrm{d} \log \mathrm{D}$ relationships. It is the size below which the pore system is depercolated, and hence plays an important role in the moisture and ionic transport properties of the material. Figure $4 \mathrm{~b}$ shows the $\mathrm{D}-\mathrm{dV} / \mathrm{d} \log \mathrm{D}$ relationships for both the plain OPC and alkali-activated pastes. The critical pore sizes for the OPC and alkali-activated paste respectively are 0.058 and $0.068 \mu \mathrm{m}$ respectively, which are very comparable, once again pointing to the similarity between these two different materials. These similarities in total pore volume and pore size can be considered to be responsible for the similarities in mechanical properties of OPC and alkali-activated mortars as shown previously in Fig. 3.

\subsection{Accelerated Chloride Transport Test Parameters}

This section discusses the accelerated chloride transport resistance of conventional and alkali-activated slag concretes
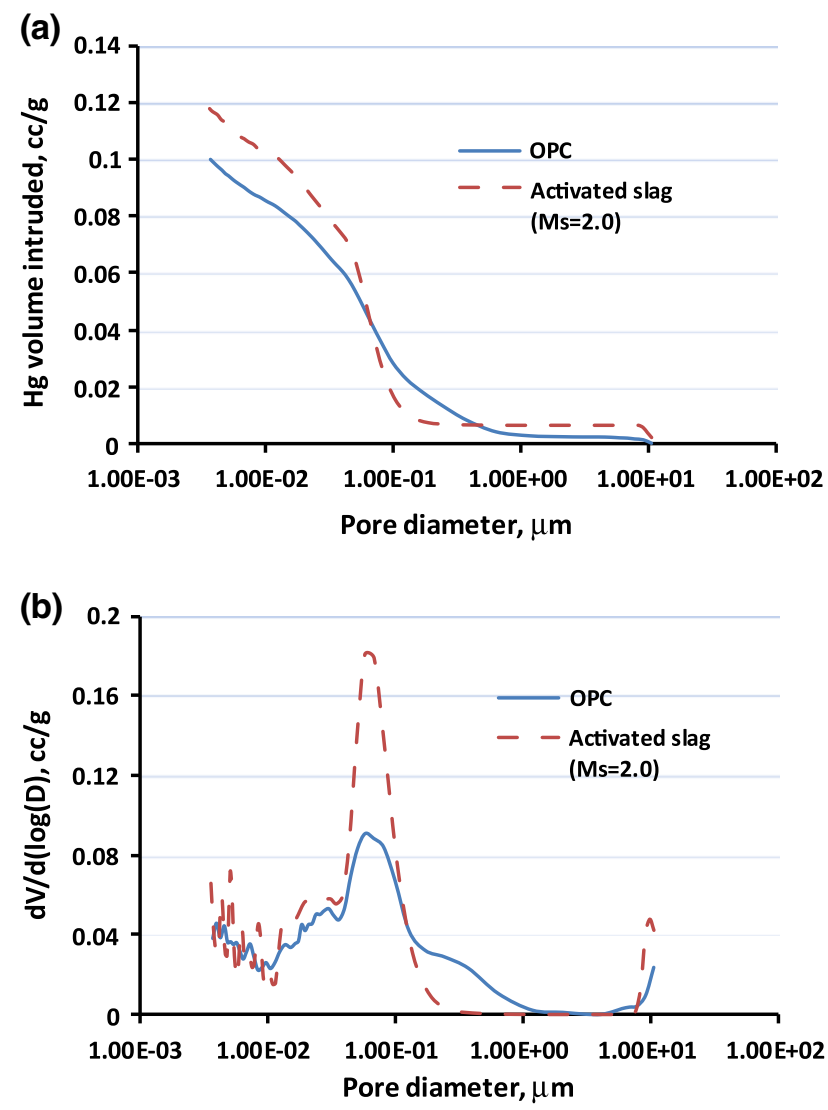

Fig. 4 a Pore diameter-pore volume relationships and b Pore diameter-differential pore volume curves for the OPC and alkali-activated slag pastes ( 28 days).

and compares their performance. Rapid chloride permeability test (RCPT) and non-steady state migration (NSSM) test are used as the transport tests. RCPT, conforming to ASTM C 1202 is one of the common durability tests used as a quality control tool and acceptance criteria for OPC concretes. RCPT measures the electrical conductivity of concretes. Conductivity of porous materials saturated with a conducting fluid is influenced by the conductivity of the saturating medium in addition to the pore structure parameters like the overall pore volume and its geometry. Thus this test does not adequately represent the pore structure characteristics of the material that determines ionic transport. This aspect has been reported elsewhere. However, its ease of use and documented relationships with other performance characteristics of concrete has made this test widely accepted in practice. The NSSM test avoids some of the drawbacks of the RCP test by using a lower applied potential and a longer test duration. The catholyte solution used is $10 \% \mathrm{NaCl}$, thereby ensuring that the catholyte concentration does not undergo large changes during the duration of the test.

Figure 5a, b shows the RCP values and NSSM coefficients as a function of curing time for the plain and modified OPC concretes. Since a number of studies have discussed chloride transport in plain and modified OPC concretes, the discussions are kept brief here, and the effort is focused on providing a comparison between these and the transport values of alkali-activated concretes. The fly ash modified concrete has a RCP value that is comparable to that of the OPC 
concrete at 28 days; however it falls well below that of the OPC concrete after 90 days of curing, pointing to the effect of pozzolanic reaction of fly ash in refining the pore structure. The use of silica fume drastically reduces the 28-day RCP values as compared to plain concrete, due to the combined effect of pore structure refinement and a reduction in pore solution conductivity. A methodology for the quantification of the contributions of pore solution conductivities and pore structure refinement to the reduction in RCP values of several concrete mixtures has been provided in (Neithalath and Jain 2010). Similar benefits are observed from Fig. $5 b$ for the NSSM coefficients also, when cement replacement materials are used.

The RCP values and NSSM coefficients of 28-day cured alkali-activated slag concretes are shown in Fig. 6, as a function of the activator $M_{s}$. In line with the trends for compressive strength (an increase with increasing $M_{s}$ ), both the RCP and NSSM values decrease with increasing $M_{s}$, providing another reason for choosing a higher $M_{s}$ value even though the early-age reaction kinetics is more favorable at lower $M_{s}$. The lower $\mathrm{Ca} / \mathrm{Si}$ ratio of the resulting reaction product, the lower total alkalinity that contributes to reduced leaching (Chithiraputhiran 2012), and the increased amounts of reaction products (Wang et al. 1994) can be considered as the reasons for this observation. The RCP values reported here are higher than those reported in another study Bernal et al. (2012), but it can possibly be attributed to the higher $n$ value of 0.10 used in that study as opposed to the $n$ value of 0.05 used here. The NSSM coefficients show a much more consistent reduction with increase in $M_{s}$, attributable to the increased dependence of NSSM coefficients on the pore structure, whereas the RCP values are dependent on the pore solution conductivity also.

When the RCP values of the alkali-activated concretes at 28 days are compared to those of OPC concretes, it can be seen that the waterglass-activated slag concretes demonstrate RCP values similar to those of 56-day cured conventional concretes or $20 \%$ fly ash modified concretes of similar w/cm. The 28 day NSSM values of the alkali-activated slag concretes of all the three $M_{s}$ values examined here are lower than those of the plain and modified OPC concretes at the same age. In fact, the 28-day NSSM coefficient of the activated concrete with an $M_{S}$ of 2.0 is similar to the 90-day NSSM coefficient of $6 \%$ silica fume modified OPC concrete. This points to the effectiveness of alkali activation of slag in reducing chloride ion transport through its microstructure, and the capability of this material to be performance-comparable to those of OPC systems. The determination of chloride diffusion coefficients of alkaliactivated slag concretes using other test methods are likely to provide widely different values (differences in 2 orders of magnitude between the NSSM coefficients reported here and the effective diffusion coefficients reported in Bernal et al. (2012), but the trends remain the same.

\subsection{Models to Establish Similarities in Material Microstructure of OPC and Activated Slag Concretes}

The foregoing sections have provided detailed accounts on the comparison between conventional cementitious binders with and without cement replacement and alkali-activated slag binders with respect to early age reactions, strength, microstructure, and chloride transport performance. In this section, electrical impedance spectroscopy (EIS) and associated electrical circuit models are used to explore the microstructures of these systems further with an aim of understanding the underlying similarities that are responsible for similar mechanical and transport properties.

\subsubsection{An Electrical Model for Material Microstructure and Its Parameters}

In order to provide reliable representations of the material microstructure, the electrical paths in the material has been

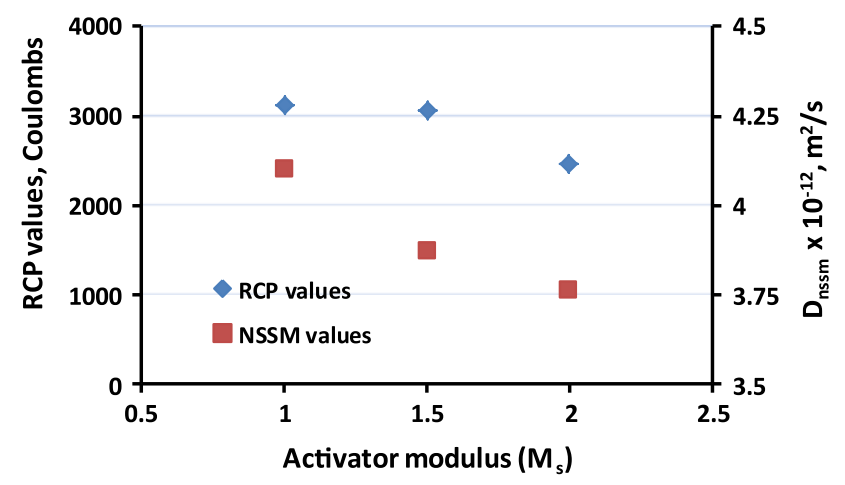

Fig. 6 RCP values and NSSM coefficients for alkali-activated slag concretes ( $n=0.05,28$ days).
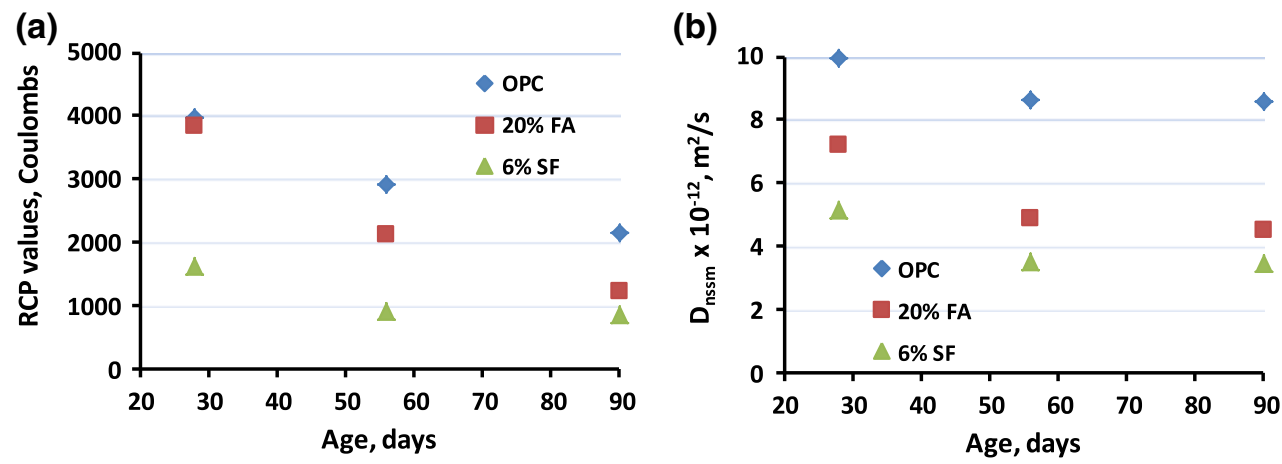

Fig. 5 a RCP values and b NSSM coefficients for plain and modified OPC concretes as a function of age. 
modeled using a combination of resistors and capacitors. One such model is shown in Fig. 7, which consists of two resistors and two capacitors, which has been shown to represent the bulk arc in the Nyquist plot of several different types of concretes (both conventional and alkali-activated) very well (Neithalath and Ravikumar 2013; Neithalath and Jain 2010; Jain and Neithalath 2011). This model has also been used in (Neithalath and Ravikumar 2013; Jain and Neithalath 2011) to identify the changes in the material microstructure induced by electrically accelerated chloride transport. The resistance $R_{c}$ is associated with the connected pores in the concrete (percolating pores), while $R_{u c}$ is the resistance of the unconnected or isolated pores in the material structure. $C_{1}$ is the dielectric capacitance related to the solid phase in the concrete (paste and the aggregates), and $C_{2}$ is the capacitance associated with the double layer present between the pore walls and the pore solution.

The total frequency dependent impedance, $Z(\omega)$ of the composite system can be stated as:

$$
Z(\omega)=\frac{Z_{1} Z_{2}}{Z_{1}+Z_{2}}
$$

where $Z_{1}$ and $Z_{2}$ are the impedances related to the $R_{c}-C_{1}$ and $R_{u c}-C_{2}$ groups in the circuit. These are denoted as:

$$
\begin{aligned}
& Z_{1}=\frac{R_{c}}{\left(1+j \omega R_{c} C_{1}\right)^{\alpha}} \\
& Z_{2}=R_{u c}\left[1+\left(j \omega R_{u c} C_{2}\right)^{-\beta}\right]
\end{aligned}
$$

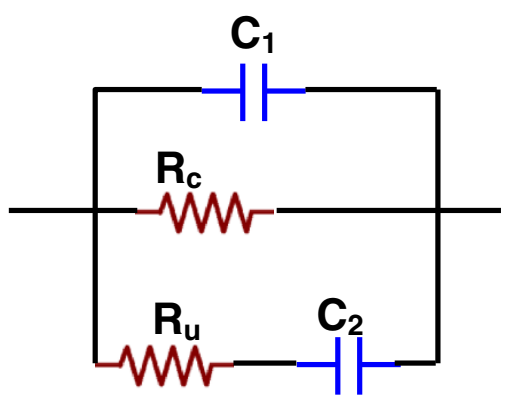

Fig. 7 A simple equivalent electrical circuit for concrete microstructure.
In these equations, the terms $\alpha$ and $\beta$ are the dispersion factors. The equivalent circuit model parameters were extracted from the impedance spectra using ZView ${ }^{\mathrm{TM}}$ software. One of the important electrical properties of concretes that can be extracted from EIS is the bulk resistance $\left(R_{b}\right)$, from which the specimen conductivity can be obtained using Eq. (3). Figure 8a shows the relationship between $R_{b}$ values measured before the start of the RCP test, and the RCP values for both the conventional and alkali-activated concretes. Two distinct relationships are noted, one for the conventional concretes and one for the alkali-activated concretes. Generally, since the RCP values are indicators of specimen conductivity, a unique relationship between RCP and $R_{b}$ is expected irrespective of the material composition and microstructure. While such a trend is observed for the conventional concretes, it is absent when all the results are considered together. This could be attributed to the differences in the relative contributions of pore structure and pore solution conductivity towards the RCP values for conventional and alkali-activated concretes. When the $R_{b}$-NSSM coefficient relationships are evaluated, there is a unique relationship irrespective of the type of concrete. The bulk resistances were measured before the start of the NSSM test in this case also. The test conditions of NSSM are designed to better capture the pore structure features (lower applied voltage that negates the joule heating effects and longer test duration) thereby making the test results more representative of the pore structure of the material.

The resistance of the connected pores $\left(R_{c}\right)$ extracted from the equivalent circuit model is one of the most important parameters that relate to the microstructure because the transport is dominated by the connected (percolating) pores. Figure 9 shows the relationship between the bulk resistance $\left(R_{b}\right)$ and the resistance of the connecting pores $\left(R_{c}\right)$ obtained before the specimens were subjected to the NSSM test. A very good linear relationship is observed between these resistances, irrespective of the concrete type. Such a result has been reported elsewhere also (Neithalath and Ravikumar 2013; Jain and Neithalath 2011). The values for the alkaliactivated concretes fall right in the range between those of plain OPC and silica fume modified concretes. When the RCP and NSSM values of alkali-activated concretes (reported earlier) are revisited, it can be noticed that those (a)

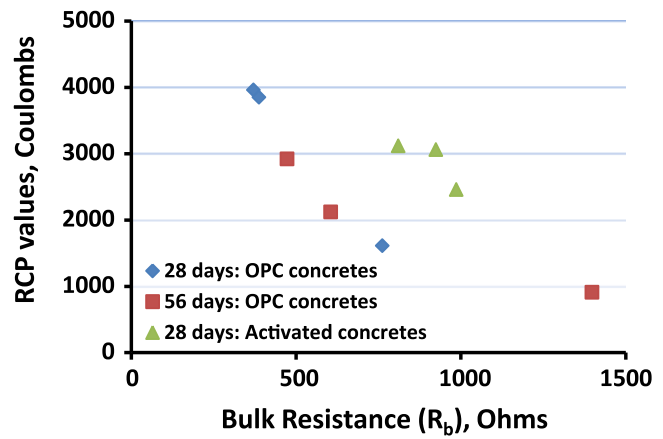

(b)

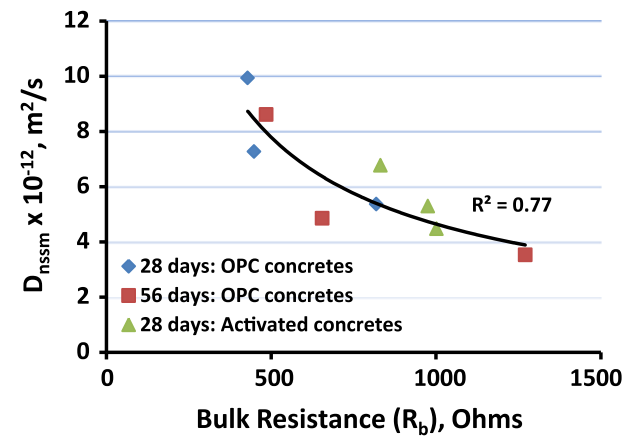

Fig. 8 Relationship between bulk resistance and: a RCP values and $\mathbf{b}$ NSSM coefficients of OPC and alkali-activated concretes. 


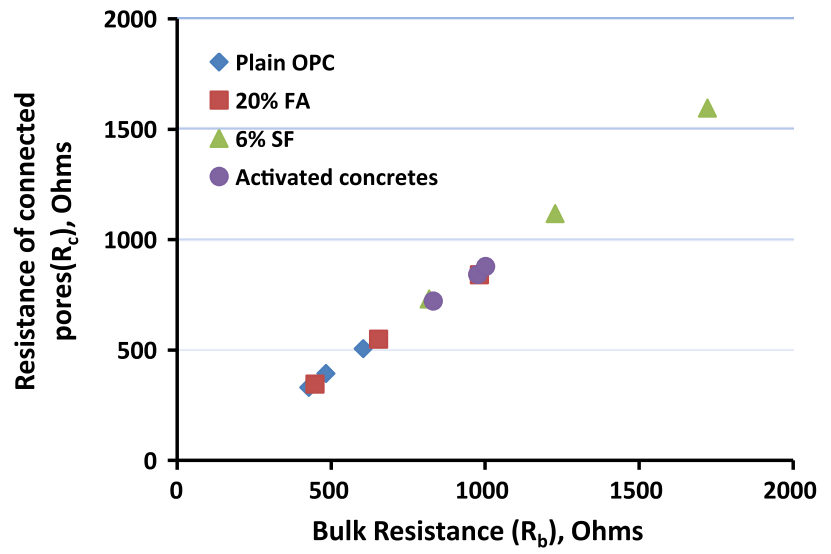

Fig. 9 Relationship between $R_{b}$ and $R_{c}$ of conventional and alkali-activated concretes.

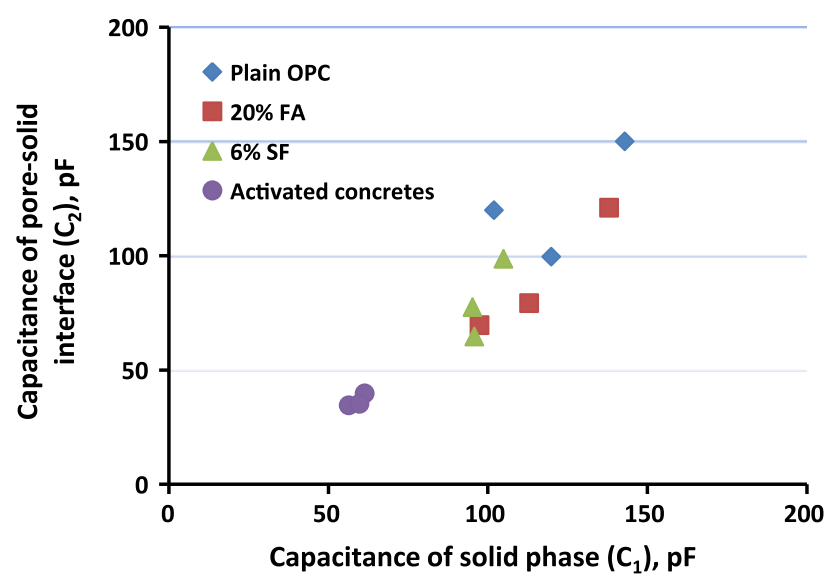

Fig. 10 Relationship between the capacitances $C_{1}$ and $C_{2}$ of conventional and alkali-activated concretes.

values also fell between those of plain OPC and silica fume modified concretes, reiterating the similarities between these materials from a pore structure and performance viewpoint. Figure 10 depicts the relationship between the capacitances - the capacitance of the solid phase $\left(C_{1}\right)$ and that of the pore-solid interface $\left(C_{2}\right)$-before the start of the NSSM test for the conventional and alkali-activated concretes. Both the capacitances of the alkali-activated concretes are found to be lower than those of the conventional concretes, potentially attributable to the differences in the stoichiometry of the reaction products and the surface charge in the solid products primarily being influenced by the alkalis sorbed on the reaction products in the activated slag pastes. However the capacitances of both the conventional and activated concretes fall along the same trend line.

\section{Conclusions}

This paper has provided results on early age reaction kinetics, strength, microstructure, and chloride transport parameters of conventional concrete systems (plain OPC and those modified with fly ash or silica fume) and waterglass activated slag concretes. It has been shown that sustainable cement-less concretes can be proportioned for similar performance characteristics. The salient conclusions with respect to different properties are summarized below.

1. Alkali-activated slag pastes showed similar isothermal calorimetric response as those of OPC pastes with respect to the characteristic features of the thermal signature. However the major reaction peak was much more delayed in the alkali-activated pastes, and exhibited lower intensities than those of OPC pastes. The overall heat released due to the alkali activation reaction was much lower than that from OPC hydration at the end of 48 or $72 \mathrm{~h}$, even though the cumulative heat release curve had not plateaued for the alkali-activated paste, especially the one with a higher $M_{s}$.

2. The compressive strengths of the alkali-activated slag mortars as proportioned in this study, and the plain and modified OPC systems were similar. For the alkaliactivated slag mortars, the 28-day compressive strength was found to be higher at higher activator $M_{s}$, which facilitates a lower $\mathrm{Ca} / \mathrm{Si}$ ratio in the $\mathrm{C}-(\mathrm{A})-\mathrm{S}-\mathrm{H}$ gel. From considerations of early age reaction kinetics and strength development, an activator $M_{s}$ of 2.0 was found to be optimal. Mercury intrusion porosimetry studies revealed that the plain OPC paste and the alkaliactivated slag paste with an $M_{s}$ of 2.0 have comparable porosities after 28 days. The critical pore size from MIP was found to be slightly lower for the OPC paste.

3. The chloride transport parameters of the alkali-activated slag concretes also showed similarities with those of OPC concretes. The 28-day cured waterglass activated slag concretes demonstrated RCP values similar to those of 56-day cured conventional concretes or $20 \%$ fly ash modified concretes of similar $\mathrm{w} / \mathrm{cm}$, while the NSSM values were similar to those of 90 -day cured $6 \%$ silica fume modified OPC concrete. This establishes the improved ionic transport resistance of alkali-activated slag concretes. Equivalent electric circuit models and associated parameters were also used to identify the similarities in the microstructure of both these types of concretes-particularly the resistance of connected pores or the percolating pore network, and the capacitances of the pore-solid interfaces.

\section{Acknowledgments}

The authors sincerely acknowledge partial financial support from National Science Foundation (CMMI: 1068985) and the New York State Energy Research and Development Authority (NYSERDA) towards the conduct of this study. The materials were provided by US Concrete, Headwaters Resources, Holcim U.S, and PQ Corporation, and are acknowledged. The work was carried out in the Laboratory for the Science and Sustainable Infrastructural Materials (LS-SIM) at Arizona State University, and the support that has made the establishment and operation of this laboratory is also acknowledged. 


\section{Open Access}

This article is distributed under the terms of the Creative Commons Attribution License which permits any use, distribution, and reproduction in any medium, provided the original author(s) and the source are credited.

\section{References}

Altan, E., \& Erdoğan, S. T. (2012). Alkali activation of a slag at ambient and elevated temperatures. Cement \& Concrete Composites, 34, 131-139.

Atahan, H. N., Oktar, O. N., \& Taşdemir, M. A. (2009). Effects of water-cement ratio and curing time on the critical pore width of hardened cement paste. Construction and Building Materials, 23, 1196-1200.

Bernal, S. A., Mejía de Gutiérrez, R., Pedraza, A. L., Provis, J. L., Rodriguez, E. D., \& Delvasto, S. (2011). Effect of binder content on the performance of alkali-activated slag concretes. Cement and Concrete Research, 41, 1-8.

Bernal, S. A., Mejía de Gutiérrez, R., \& Provis, J. L. (2012). Engineering and durability properties of concretes based on alkali-activated granulated blast furnace slag/metakaolin blends. Construction and Building Materials, 33, 99-108.

Chang, J. J. (2003). A study on the setting characteristics of sodium silicate-activated slag pastes. Cement and Concrete Research, 33, 1005-1011.

Chithiraputhiran, S. (2012). Kinetics of alkali activation of slag and fly ash-slag systems. M.S Thesis, Arizona State University, 2012, Tempe, AZ.

Chithiraputhiran, S., \& Neithalath, N. (2013). Isothermal reaction kinetics and alkali activation of slag, fly ash, and their blends. Construction and Building Materials, 45, 233-242.

Diamond, S. (2000). Mercury porosimetry: An inappropriate method for the measurement of pore size distributions in cement-based materials. Cement and Concrete Research, 30, 1517-1525.

Duxson, P., Fernández-Jiménez, A., Provis, J., Lukey, G., Palomo, A., \& van Deventer, J. S. J. (2007). Geopolymer technology: The current state of the art. Journal of Materials Science, 42, 2917-2933.

Fernández-Jiménez, A., Palomo, J. G., \& Puertas, F. (1999). Alkali-activated slag mortars: Mechanical strength behaviour. Cement and Concrete Research, 29, 1313-1321.

Hajimohammadi, A., Provis, J. L., \& van Deventer, J. S. J. (2011). The effect of silica availability on the mechanism of geopolymerisation. Cement and Concrete Research, 41, 210-216.

Jain, J., \& Neithalath, N. (2011). Electrical impedance analysis based quantification of microstructural changes in concretes due to non-steady state chloride migration. Materials Chemistry and Physics, 129, 569-579.

Kumar, A., Oey, T., Falla, G. P., Henkenseifken, R., Neithalath, N., \& Sant, G. (2013). A comparison of intergrinding and blending limestone on reaction and strength evolution in cementitious materials. Construction and Building Materials, 43, 428-435.

Mehta, P. K. (2007). Sustainability of the concrete industryCritical issues, ACI Strategic Development Committee's. Concrete Summit on Sustainable Development, March 29, Washington, DC.

Moro, F., \& Böhni, H. (2002). Ink-bottle effect in mercury intrusion porosimetry of cement-based materials. Journal of Colloid and Interface Science, 246, 135-149.

Neithalath, N., \& Jain, J. (2010). Relating rapid chloride transport parameters of concretes to microstructural features extracted from electrical impedance. Cement and Concrete Research, 40, 1041-1051.

Neithalath, N., Persun, J., \& Hossain, A. (2009). Hydration in high-performance cementitious systems containing vitreous calcium aluminosilicate or silica fume. Cement and Concrete Research, 39, 473-481.

Neithalath, N., \& Ravikumar, D. (2013). Evaluating the use of accelerated test methods for chloride transport in alkali activated slag concretes using electrical impedance and associated models. ASTM STP 1566.

NT Build 492 (1999). Concrete, mortar and cement-based repair materials: chloride migration coefficient from non-steadystate migration experiments. NordtestProj, Espoo.

Pacheco-Torgal, F., Abdollahnejad, Z., Camões, A. F., Jamshidi, M., \& Ding, Y. (2012). Durability of alkali-activated binders: A clear advantage over Portland cement or an unproven issue? Construction and Building Materials, 30, 400-405.

Pacheco-Torgal, F., Castro-Gomes, J., \& Jalali, S. (2008). Alkali-activated binders: A review: Part 1. Historical background, terminology, reaction mechanisms and hydration products. Construction and Building Materials, 22, 1305-1314.

Palomo, A., Grutzeck, M., \& Blanco, M. (1999). Alkali-activated fly ashes: A cement for the future. Cement and Concrete Research, 29, 1323-1329.

Provis, J. L., \& Van Deventer, J. S. J. (2009). Geopolymers: Structure, processing, properties and industrial applications. Cambridge, UK: Woodhead.

Puertas, F., Fernández-Jiménez, A., \& Blanco-Varela, M. T. (2004). Pore solution in alkali-activated slag cement pastes. Relation to the composition and structure of calcium silicate hydrate. Cement and Concrete Research, 34, 195-206.

Ravikumar, D., \& Neithalath, N. (2012a). Reaction kinetics in sodium silicate powder and liquid activated slag evaluated using isothermal calorimetry. Thermochimica Acta, 546, 32-43.

Ravikumar, D., \& Neithalath, N. (2012b). Effects of activator characteristics on the reaction product formation in slag binders activated using alkali silicate powder and $\mathrm{NaOH}$. Cement \& Concrete Composites, 34, 809-818.

Ravikumar, D., \& Neithalath, N. (2013). Electrically induced chloride ion transport in alkali activated slag concretes and the influence of microstructure. Cement and Concrete Research, 47, 31-42.

Ravikumar, D., Peethamparan, S., \& Neithalath, N. (2010). Structure and strength of $\mathrm{NaOH}$ activated concretes 
containing fly ash or GGBFS as the sole binder. Cement \& Concrete Composites, 32, 399-410.

Schwarz, N., \& Neithalath, N. (2010). Chloride transport in glass powder and fly ash modified concretes-Influence of test methods on microstructure. Cement \& Concrete Composites, 32, 148-156.

Shi, C., Krivenko, P. V., \& Roy, D. (2006). Alkali-activated cements and concretes. London, UK: Spon Press.

Song, S., Sohn, D., Jennings, H. M., \& Mason, T. O. (2000). Hydration of alkali-activated ground granulated blast furnace slag. Journal of Material Science, 35, 249-257.
Vance, K., Aguayo, M., Oey, T., Sant, G., \& Neithalath, N. (2013). Hydration and strength development in ternary portland cement blends containing limestone and fly ash or metakaolin. Cement \& Concrete Composites, 39, 93-103.

Wang, S., Scrivener, K. L., \& Pratt, P. L. (1994). Factors affecting the strength of alkali-activated slag. Cement and Concrete Research, 24, 1033-1043.

Yip, C. K., Lukey, G. C., \& van Deventer, J. S. J. (2005). The coexistence of geopolymeric gel and calcium silicate hydrate at the early stage of alkaline activation. Cement and Concrete Research, 35, 1688-1697. 